Check for updates

Cite this: RSC Adv., 2017, 7, 39075

Received 22nd June 2017

Accepted 31st July 2017

DOI: $10.1039 / \mathrm{c} 7 \mathrm{ra06962f}$

rsc.li/rsc-advances

\section{Bacteria-white-rot fungi joint remediation of petroleum-contaminated soil based on sustained- release of laccase}

\begin{abstract}
Boqun Liu, ${ }^{a}$ Jinpeng Liu, (DD ${ }^{* b}$ Meiting Ju, ${ }^{b}$ Xiaojing Li ${ }^{c}$ and Ping Wang ${ }^{b}$
In this work, a new model of a bioremediation system for petroleum-contaminated soil was developed which had a TPH degradation rate of $57.72 \pm 5.55 \%$ after 30 days of remediation. In this system, petroleum-degrading bacteria combined with white-rot fungi were applied to the remediation of petroleum-contaminated soil. Instead of spraying a fungal suspension, through solid-state fermentation (SSF), the white-rot fungi first formed a remediation material which could continuously secrete key enzymes under special stimulation, which could then be used in the remediation after reaching the steady structure of a white-rot fungi carrier (after SSF). The white-rot fungi remediation material was designed to be placed inside or on the surface of the soil, and it degraded the petroleum hydrocarbons simultaneously with the bacteria in the soil. The enzyme secretions of white-rot fungi during the SSF and fungi remediation material during the petroleum-contaminated soil remediation were analysed. In addition, sand, straw and biosurfactants were added to assist the bioremediation to optimize the bacteria-white-rot fungi joint remediation system. Orthogonal experiments were also performed to study the effect of different factors in the remediation.
\end{abstract}

\section{Introduction}

The development of the petroleum industry has significantly promoted the growth of the global economy. However, in the exploitation, transportation, and processing of oil, large volumes of petroleum hydrocarbons have contaminated the environment because of oil spillages and accidents. ${ }^{1}$ At present, many areas have been subjected to ecological risk from petroleum-contaminated soil., ${ }^{2,3}$ There are many toxic, harmful components found in petroleum pollution, such as benzene, ethylbenzene, toluene, and xylenes (BETX), which threaten human health and the soil eco-system. ${ }^{4-6}$ Currently, remediation measures for petroleum-contaminated soil mainly include physical, chemical, and biological methods. ${ }^{7-10}$

As a type of bioremediation technology, microbial remediation, including bioaugmentation or biostimulation, biodegrades petroleum hydrocarbons contained in petroleum-contaminated soil by using the growth activities of microorganisms. ${ }^{11-14}$ In research on the remediation of petroleum-contaminated soil, researchers have found many microorganisms which can be used to biodegrade petroleum hydrocarbons. Of these, there are

${ }^{a}$ Laboratory of Environmental Protection in Water Transport Engineering, Tianjin Research Institute of Water Transport Engineering, Tianjin 300456, China

${ }^{b}$ College of Environmental Science and Engineering, Nankai University, Tianjin 300350, PR China

${ }^{c}$ Agro-Environmental Protection Institute, Ministry of Agriculture, Tianjin 300191, PR China bacteria separated from petroleum-contaminated soil which grow with petroleum hydrocarbons as their carbon source, ${ }^{15,16}$ and white-rot fungi which degrade petroleum hydrocarbons by secreting degrading enzymes, like lignin peroxidase (LiP), manganese peroxidase (MnP) and laccase. ${ }^{17-22}$ With different physiological characteristics, bacteria and white-rot fungi present dissimilar features in the remediation of petroleumcontaminated soil. With their simple structures and small size, bacteria show strong adaptability to environmental change and are easily propagated. However, their capacity to degrade petroleum hydrocarbons with complex structures is poor. In contrast, as eukaryotes, white-rot fungi require a higher nutrition level for growth, but have a higher-grade oxidase system presenting better degradation ability for complex petroleum hydrocarbons. ${ }^{23-26}$

Considering the bad environmental conditions like the high oil and salt content, using bacteria and white-rot fungi alone cannot guarantee a good remediation effect. Relevant research has indicated that a combined remediation technique for soil could produce a better remediation effect.9,27-29

Therefore, to solve the above problems, this research adopted a new way for white-rot fungi to play a full part in the degradation ability of both bacteria and fungi, with other factors, and designed a new remediation system combining bacteria and white-rot fungi.

In this system, a fungal remediation material was formed through SSF of white-rot fungi, which had better stability and enzyme production efficiency. By covering the soil surface or 
inserting fungal remediation material into the soil, this system slowly released degrading enzymes to the soil. Meanwhile, by applying bacteria with a high degradation capacity for petroleum hydrocarbons in the soil, the joint degradation thereof was realised. In the meantime, sand and straw were added to improve the physical, and chemical, properties of the soil. Moreover, biosurfactants were added to increase the solubility of the petroleum hydrocarbon in the soil. Finally, by performing orthogonal experiments, the mutual effects of each component in the remediation of soil were studied.

\section{Methods and materials}

\subsection{Soil sampling and organism}

The petroleum-contaminated soil used was artificially made and obtained from Nankai University in Tianjin, China. The oil used was collected from an oil pipeline in the Dagang oilfield, Tianjin. After being dehydrated by exposure to sunlight for $3 \mathrm{~d}$, the soil was filtered using a 50 mesh screen; while the acquired oil stood at $25{ }^{\circ} \mathrm{C}$ for $5 \mathrm{~d}$ to separate the soil from the water. Afterwards, the oil was dissolved in petroleum ether whose boiling point is $30{ }^{\circ} \mathrm{C}$ to $60{ }^{\circ} \mathrm{C}$ and then uniformly mixed with the soil. Finally, the mixture was air-dried until the petroleum ether was completely volatilized for further study. The measurement results showed that the total petroleum hydrocarbon (TPH) content in the petroleum-contaminated soil was $2.5 \%$.

In this study, the bacterium used for degrading petroleum hydrocarbon was the strain of Bacillus licheniformis Y-1, which was isolated from petroleum-contaminated soil found near the production platform of Dagang Oilfield and preserved in Nankai University, stored in T-medium slants at $4{ }^{\circ} \mathrm{C}$. The whilerot fungus used in the experiments was Pleurotus ostreatus P1 preserved in Nankai University, which was stored in potato dextrose agar (PDA) slants at $4{ }^{\circ} \mathrm{C}$.

\subsection{Experiment design}

The remediation system used here included these components: B. licheniformis $\mathrm{Y}-1, P$. ostreatus $\mathrm{P} 1$, sand, straw and biosurfactant. To study the effects of each component, orthogonal experiments were designed, as shown in Table 1:

Table 1 Remediation experiment design

\begin{tabular}{llllll}
\hline & P1 & & & & \\
\cline { 2 - 5 } Y-1 & Liquid & Solid & & & \\
liquid & state & state & Sand & Straw & Biosurfactant \\
\hline
\end{tabular}

\begin{tabular}{|c|c|c|c|c|c|}
\hline \multicolumn{6}{|c|}{ CP } \\
\hline A & $\checkmark$ & & & & \\
\hline B & & & $\checkmark$ & & \\
\hline $\mathrm{C}$ & $\checkmark$ & & & $\checkmark$ & $\checkmark$ \\
\hline $\mathrm{D}$ & & & $\checkmark$ & $\checkmark$ & $\checkmark$ \\
\hline $\mathrm{E}$ & & $\checkmark$ & & $\checkmark$ & $\checkmark$ \\
\hline $\mathrm{F}$ & $\checkmark$ & & & $\checkmark$ & $\checkmark$ \\
\hline $\mathrm{G}$ & & & $\checkmark$ & $\checkmark$ & $\checkmark$ \\
\hline $\mathrm{H}$ & $\checkmark$ & & $\checkmark$ & $\checkmark$ & $\checkmark$ \\
\hline
\end{tabular}

In the above experiments, $500 \mathrm{~g}$ of petroleum-contaminated soil was added. $5 \%$ sand $(\mathrm{m} / \mathrm{m}), 5 \%$ straw $(\mathrm{m} / \mathrm{m})$, and $5 \%$ biosurfactant $(\mathrm{V} / \mathrm{m})$ were added to the corresponding groups. As for the inoculated contents, $2 \%$ of bacterial inoculants $(\mathrm{V} / \mathrm{m})$ and $5 \%$ of fungal liquid inoculants $(\mathrm{V} / \mathrm{m})$ were applied to the system. The fungal remediation materials placed on the soil were $1 \mathrm{~cm}$ thick. The control group used the same operation as in other experimental groups.

The soil, which was 1 to $2 \mathrm{~cm}$ below the soil surface, was sampled every five days to detect each index.

\subsection{SSF of white-rot fungus: $P$. ostreatus $P 1$}

After being activated, P. ostreatus P1 was placed in potato dextrose agar (PDA) liquid medium for shaking-culture at $120 \mathrm{rpm}$, at $25{ }^{\circ} \mathrm{C}$, for $5 \mathrm{~d}$. Then, the fermentation broth was centrifuged at $6000 \mathrm{rpm}$ to obtain the thalli. Then the $P$. ostreatus P1 broth was inoculated into the bacteria-free material which was composed of straw, sawdust, and wheat bran in a proportion of $7: 2: 1$, using sterile water to adjust the humidity to $60 \%$. Then the SSF was incubated at $27 \pm 1{ }^{\circ} \mathrm{C}$ and $60 \%$ humidity. The material was sampled daily to detect laccase activity and to observe the growth of the P. ostreatus P1 mycelia.

The laccase activity was defined, and calculated, as follows: $10 \mathrm{ml}$ of deionised water were used to extract laccase from $1 \mathrm{~g}$ of wet fungal material by using a total antioxidant capacity assay kit with a rapid ABTS method. The reaction system was composed of $1 \mathrm{ml}$ of buffer solution, $1 \mathrm{ml}$ of ABTS solution, and $1 \mathrm{ml}$ of crude enzyme. The OD600 value was recorded at $25{ }^{\circ} \mathrm{C}$ after zero-adjustment of the spectrophotometer at $420 \mathrm{~nm}$. For the evaluation of laccase activity, one activity unit was defined as the amount of enzyme necessary to oxidise $1 \mu \mathrm{mol}$ of ABTS per minute. Each value presented here represents the mean of three replicates. ${ }^{\mathbf{2 6 , 3 0}}$ Then, $1 \mathrm{~g}$ of fungal material was dried at $40{ }^{\circ} \mathrm{C}$ to detect the moisture content so as to modify the laccase activity.

\subsection{Preparation of $B$. licheniformis Y-1 for degrading petroleum}

Based on the previous research, ${ }^{31}$ B. licheniformis $\mathrm{Y}-1$ has strong petroleum hydrocarbon-degrading capacity. Moreover, it can generate biosurfactants at high temperatures. After isolation, purification, FT-IR and ${ }^{1} \mathrm{H}$ NMR analysis, the obtained biosurfactant is a cyclic lipopeptide, which can reduce the surface tension of deionised water from $82 \mathrm{mN} \mathrm{m}^{-1}$ to $27 \mathrm{mN} \mathrm{m}^{-1}$, and it significantly improved the petroleum-contaminated soil remediation in our previous study. ${ }^{32}$ The biosurfactant would be used in the remediation experiment, as shown in Table 1.

After activation, B. licheniformis Y-1 was inoculated into the T-medium to undergo shaking-culture at $35{ }^{\circ} \mathrm{C}$ and $120 \mathrm{rpm}$ for $4 \mathrm{~d}$. Then, the fermentation broth was centrifuged at $6000 \mathrm{rpm}$. After being washed with deionised water, the obtained thalli precipitation was re-centrifuged at $8000 \mathrm{rpm}$ to roughly discard the nutriments contained in the medium. Finally, the obtained thalli precipitation was dissolved in deionised water in the proportion of $1: 5(\mathrm{~m} / \mathrm{v})$ to prepare bacterial liquid inoculants. 


\subsection{The effect of laccase to B. licheniformis Y-1}

To detect the influence of laccase on the growth of B. licheniformis $\mathrm{Y}-1$, B. licheniformis $\mathrm{Y}-1$ was inoculated into the T-medium at $35^{\circ} \mathrm{C}$ and $120 \mathrm{rpm}$ with laccase. The crude enzyme extracted from the fungal remediation material was filtered through a membrane with an aperture size of $0.45 \mu \mathrm{m}$ which was then added to the medium. Moreover, a control group without laccase was used to determine the growth curve of the B. licheniformis $\mathrm{Y}-1$, and another control group containing only laccase was used to observe the changes in laccase activity and the stability of laccase in water. In this experiment, the initial laccase activity was $13.5 \mathrm{U} \mathrm{l}^{-1}$.

\subsection{Assay of orthogonal experiments}

The soil electrical conductivity (EC) was determined as follows: after being dried at $40{ }^{\circ} \mathrm{C}$, the soil was filtered through a 100 mesh. The obtained material was dissolved in deionised water in a proportion of $1: 10(\mathrm{~m} / \mathrm{v})$. Then the obtained solution was shocked sufficiently at $25{ }^{\circ} \mathrm{C}$ and $180 \mathrm{rpm}$ for $2 \mathrm{~h}$. After centrifugation of the solution at $10000 \mathrm{rpm}$, the EC of the supernatant was tested..$^{33}$

To determine the laccase activity, $1 \mathrm{~g}$ of wet soil was dissolved in deionised water in a proportion of $1: 10(\mathrm{~m} / \mathrm{v})$. The solution was sufficiently shocked at $25^{\circ} \mathrm{C}$ and $180 \mathrm{rpm}$ for $2 \mathrm{~h}$, followed by centrifugation at $10000 \mathrm{rpm}$. Afterwards, the supernatant was obtained to detect the laccase activity using the method proposed in Section 2.3. In addition, $1 \mathrm{~g}$ of wet soil was dried at $40{ }^{\circ} \mathrm{C}$ to be used to determine the moisture content. In this way, the laccase activity was modified.

The degradation rates for TPH and polycyclic aromatic hydrocarbons (PAHs) were calculated as follows: after being dried at $40{ }^{\circ} \mathrm{C}$, the soil was screened through a 100 mesh filter. Then, by using dichloromethane as the extractant, petroleum hydrocarbons were extracted using Soxhlet extraction, followed by a determination of the degradation rate for TPH using the weight difference method. Afterwards, the petroleum hydrocarbons were dissolved in $5 \mathrm{ml}$ of $n$-hexane and filtered through a silica gel column to separate the PAHs. Finally, the degradation rate for PAHs was measured by using the weight difference method. ${ }^{11}$

The separated PAHs were dissolved in dichloromethane. After dilution, the contents of these 16 types of PAHs were detected using GC-MS. The measurements of 16 priority PAHs were performed on a gas chromatograph (GC, Agilent 7890 GC, US) with helium as the carrier gas $\left(1 \mathrm{~mL} \mathrm{~min}^{-1}\right)$. The gas chromatograph was equipped with a Thermo Scientific TRA CETR-5MS GC Column with length, internal diameter, and film thickness of $30 \mathrm{~m}, 0.25 \mathrm{~mm}$, and $0.25 \mu \mathrm{m}$, respectively. The following temperature program was used for PAHs measurements: $70{ }^{\circ} \mathrm{C}$ for $1 \mathrm{~min}$, then increased at $10{ }^{\circ} \mathrm{C} \min ^{-1}$ to $260{ }^{\circ} \mathrm{C}$ and held for $4 \mathrm{~min}$; then increased at $5{ }^{\circ} \mathrm{C} \min ^{-1}$ to $300{ }^{\circ} \mathrm{C}$, followed by $4 \mathrm{~min}$ of heat preservation. ${ }^{11}$

\section{Results and discussion}

\subsection{Changes in laccase activity during $P$. ostreatus P1 SSF}

The degradation of petroleum hydrocarbon by white-rot fungi mainly occurs extracellularly. This is because this process is performed by the degrading enzymes system secreted outside by white-rot fungi during their growth, and laccase is one of the important components of the system. ${ }^{34}$ To provide continuous laccase with high activity for the remediation of petroleumcontaminated soil, this research monitored the changes in laccase activity during SSF of $P$. ostreatus $\mathrm{P} 1$, and then applied the fungal material with high laccase productivity for soil remediation. In the experiment, it was found that on the $15^{\text {th }}$ day, the mycelia of the P. ostreatus P1 overgrew the straw and formed a fungal layer with large density and high stability. On the $18^{\text {th }}$ day, the laccase activity of the fungal material reached its highest point at $1.03 \mathrm{U} \mathrm{g}^{-1}$ (Fig. 1), then gradually decreased. Compared with other research results, the $P$. ostreatus P1 used in this study showed higher laccase production abilities. For instance, the highest laccase activity of the strain of Ganoderma lucidum used by Liao et al. for degrading toxic organic substances was $0.8 \mathrm{U} \mathrm{g}^{-1} \cdot{ }^{26}$ Therefore, the authors selected the material through SSF after more than 18 days as the remediation material which showed good enzyme productivity.

\subsection{EC changes during remediation}

As one of important physical and chemical characteristics of the soil, the EC represents the amount of soluble salt(s) in the soil. Too low an EC is supposed to influence the fertility of soil. Detection indicated that the EC of the soil used here was $245 \mu \mathrm{m} \mathrm{cm}^{-1}$, which was relatively low.

As shown in Fig. 2, it can be seen that after microbial remediation, the EC of the soil was apparently improved and reached a maximum on the $15^{\text {th }}$ day. Moreover, the EC remained relatively stable after the $20^{\text {th }}$ day. This suggested that the activities of the microorganism had influenced the EC of the soil. This was attributed to the large amount of inorganic salt contained in the metabolites of the microorganisms; while the reduction in EC after 15 days was possibly a result of the consumption of inorganic salt in the soil by the growth of the microorganisms. Meanwhile the growth of inoculating microbes made the soluble inorganic salt stabilise at a higher concentration.

As shown in Fig. 2(a), the EC of the soil was increased from $245 \mu \mathrm{m} \mathrm{cm}^{-1}$ to $400 \mu \mathrm{m} \mathrm{cm}^{-1}$ after sand and straw were added, which indicated that there were large amounts of soluble inorganic salts in the sand. While, as can be seen from Fig. 2(c) and (d), almost no influence was found on the soil EC after the

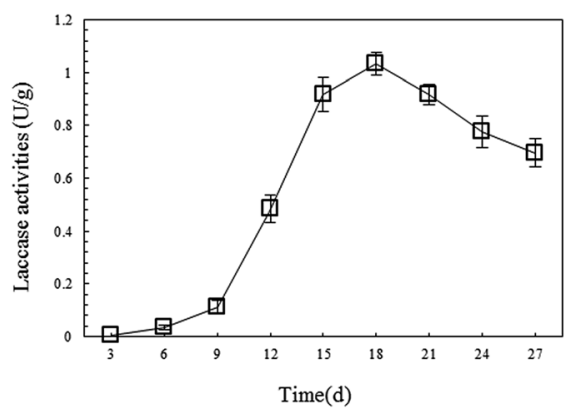

Fig. 1 Changes in laccase activity during $P$. ostreatus P1 SSF. 

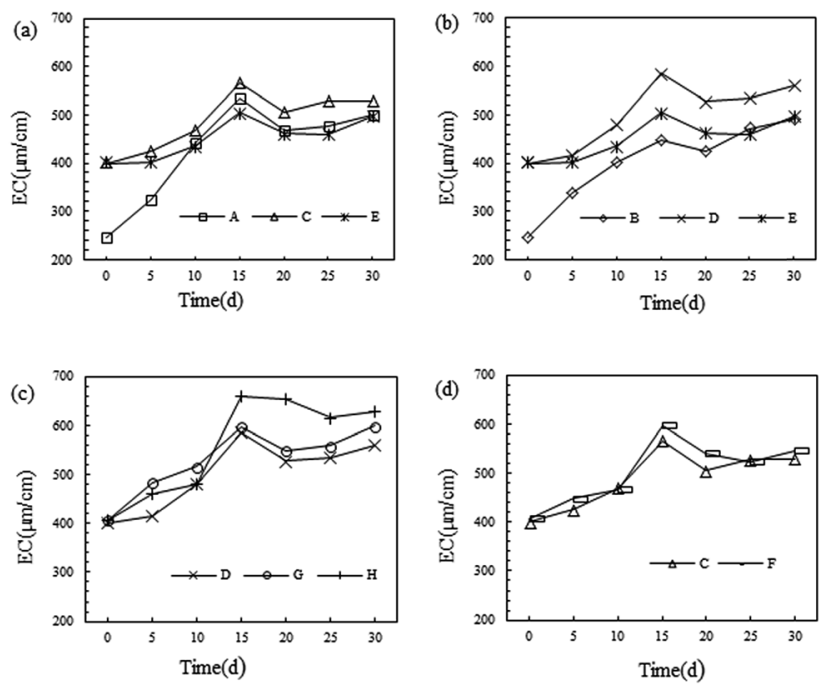

Fig. 2 EC changes of each group, $A \backslash C \backslash E$ in (a), $B \backslash D \backslash E$ in (b), $D \backslash G \backslash H$ in (c), C\F in (d)

addition of the biosurfactant. This was mainly because the biosurfactants are primarily composed of glycoprotein. During the remediation process, the biosurfactant accelerated the remediation of bacteria and fungi, owing to the biosurfactant increasing the solubility of petroleum hydrocarbons in the soil and thus providing a greater carbon source for the metabolism of microorganisms, thus promoting the remediation effect. Numerous studies have proven that biosurfactants play an important role in accelerating the remediation of petroleumcontaminated soil. ${ }^{35,36}$

Moreover, as demonstrated in Fig. 2(a), B. licheniformis Y-1 presents a better promoting effect on the EC of soil than P. ostreatus $\mathrm{P} 1$, which may be attributable to the higher content of soluble inorganic salt in the metabolites of the bacteria. Based on Fig. 2(b), compared with the method of directly inoculating $P$. ostreatus $\mathrm{P} 1$ solution into the soil, the fungal remediation material can produce a better increase in the EC. This was possibly because during the downward movement of water, inorganic salts generated by the metabolism of $P$. ostreatus $\mathrm{P} 1$ in the fungal remediation material were carried to the soil. In addition, by analysing Fig. 2(c), in group $\mathrm{H}$, when using the proposed bacteria-white-rot fungi joint remediation, there was optimal improvement in soil EC, reaching $660 \mu \mathrm{m} \mathrm{cm}^{-1}$ on the $15^{\text {th }}$ day and $629 \mu \mathrm{m} \mathrm{cm}^{-1}$ after remediation for 30 days.

\subsection{Laccase activity changes during remediation}

Numerous studies have revealed that laccase has a strong ability to degrade petroleum hydrocarbons. This effect is realised by breaking the chemical bonds of molecules in the petroleum hydrocarbons through oxidation, especially for PAHs which are difficult to degrade..$^{18,22,34}$ Therefore, continuously obtaining laccase with a high activity is the key to the remediation of petroleum-contaminated soil by white-rot fungi.

Compared to the SSF of $P$. ostreatus $\mathrm{P} 1$, the highest laccase activity of the fungal material shown in Fig. 3 was obviously at
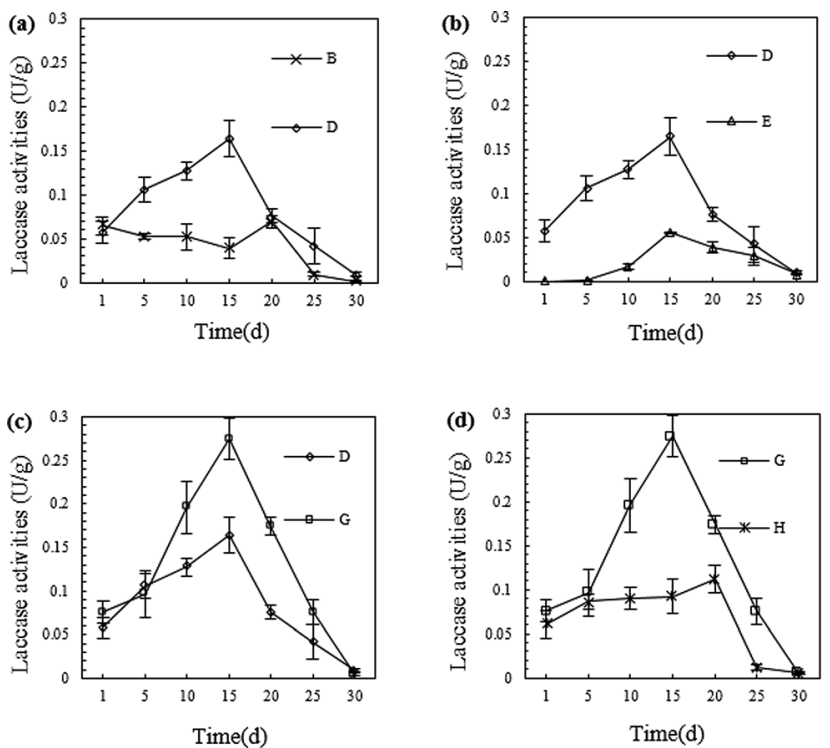

Fig. 3 Laccase activity changes of each group, $B \backslash D$ in (a), $D \backslash E$ in (b), $\mathrm{D} \backslash \mathrm{G}$ in (c), G\H in (d).

a lower level. The much worse condition of petroleumcontaminated soil than that of the SSF may have caused the decline of the fungal material's enzymes production ability. But along with the adaptation of the fungal material to the petroleum-contaminated soil, and the stimulation of the petroleum hydrocarbons to the fungal material, the laccase secretion by $P$. ostreatus $\mathrm{P} 1$ gradually increased. ${ }^{\mathbf{1 8 , 2 2}}$

As shown in Fig. 3, the laccase activity therein gradually increased and reached a maximum on the $15^{\text {th }}$ to $20^{\text {th }}$ days, and then slowly decreased thereafter. Furthermore, the laccase activity in group $\mathrm{H}$ (with the application of fungi, straw, sand, and biosurfactant) on the $15^{\text {th }}$ day was the highest in the experiments, namely, $0.27 \mathrm{U} \mathrm{g}^{-1}$.

As shown in Fig. 3(a), after straw was added to the soil, the laccase activity therein increased. This was possibly because, during the downward permeation to the lower soil layer from the fungal material layer, water carried laccase and a certain amount of $P$. ostreatus P1 into the soil; while it may also have resulted from the $P$. ostreatus $\mathrm{P} 1$ growing between the fungal material layer and the soil. After adding straw, P. ostreatus P1 grew and dispersed into the soil by using the straw in the soil as an organic framework, and generated additional laccase in the growth process. As can be seen from Fig. 3(b), the inoculation mode of $P$. ostreatus $\mathrm{P} 1$ can also influence the laccase content in the soil: there was more laccase found in group $\mathrm{D}$, which used more fungal remediation materials than that in group E, which adopted a traditional inoculation mode. With the addition of biosurfactant, the laccase activity in the soil was further improved, as shown in Fig. 3(c). This was probably because the biosurfactant accelerated $P$. ostreatus $\mathrm{P} 1$ activity in the soil, which tallied with the analysis of the EC results (Fig. 2). According to Fig. 3(d), the laccase activity in group $\mathrm{H}$, which was inoculated with $B$. licheniformis $\mathrm{Y}-1$, was significantly lower than that in group $\mathrm{G}$ (without inoculation of $B$. licheniformis Y-1). Especially 5 days after remediation, the difference increased gradually. It can be 
speculated that this was caused by the degradation of a certain amount of laccase by B. licheniformis Y-1 in the soil.

\subsection{The effect of laccase to $B$. licheniformis $\mathrm{Y}-1$}

To verify the speculation in Section 3.3, two experiments were used to study the mutual effect between laccase and the B. licheniformis Y-1 used in the degradation of petroleum hydrocarbon.

As can be seen in Fig. 4(a), with increasing fermentation time, the B. licheniformis $\mathrm{Y}-1$ biomass in the fermentation broth gradually increased, while the laccase activity gradually decreased. In contrast, in the control group, laccase showed a favourable stability. This indicated that when there were insufficient nutrients able to be readily utilised, such as carbohydrate, in the culture environment, the B. licheniformis Y1 was able to grow using laccase, which validated the previous speculation. That is, during the remediation process, B. licheniformis Y-1 in the soil consumed a certain amount of the laccase generated by the $P$. ostreatus P1. Based on Fig. 4(b), it was found that the $B$. licheniformis Y-1 biomass was reduced after laccase, at a high concentration, was added. This suggested that laccase, at a high concentration, was toxic to the growth of $B$. licheniformis Y-1, which was possibly related to its strong oxidizability. Therefore, in the actual remediation process, the concentration of laccase in the soil can directly influence the growth of $B$. licheniformis $\mathrm{Y}-1$ and therefore affect the degradation of petroleum hydrocarbons. ${ }^{37,38}$

\subsection{Degradation effect on petroleum hydrocarbons}

After 30 days of remediation, the laccase activity in the soil was reduced to a low level, and most straw in the fungal remediation material was decomposed by $P$. ostreatus $\mathrm{P} 1$. Therefore, the remediation was ended at the $30^{\text {th }}$ day to determine the degradation effect on petroleum hydrocarbons.

According to the results shown in Fig. 5(a), by sorting these nine groups based on their degradation rates for TPH, it was found that: $\mathrm{H}(57.72 \pm 5.55 \%)>\mathrm{G}(54.01 \pm 4.39 \%)>\mathrm{D}$ $(50.65 \pm 2.99 \%)>\mathrm{E}(49.31 \pm 9.38 \%)>\mathrm{F}(45.41 \pm 7.31 \%)>\mathrm{C}$ $(42.18 \pm 5.33 \%)>\mathrm{B}(41.41 \pm 4.27 \%)>\mathrm{A}(39.06 \pm 6.35 \%)>\mathrm{CP}$ $(3.05 \pm 0.63 \%)$. Moreover, the degradation rate for total PAH was: $\mathrm{H}(49.05 \pm 6.49 \%)>\mathrm{G}(45.08 \pm 6.63 \%)>\mathrm{D}(40.68 \pm$ $3.14 \%)>\mathrm{E}(36.72 \pm 5.82 \%)>\mathrm{B}(33.93 \pm 2.95 \%)>\mathrm{F}(25.21 \pm$ $3.39 \%)>\mathrm{C}(20.95 \pm 2.77 \%)>\mathrm{A}(13.59 \pm 2.02 \%)>\mathrm{CP}(1.26 \pm$ $0.28 \%$ ). Group $\mathrm{H}$, which used the bacteria-fungi joint
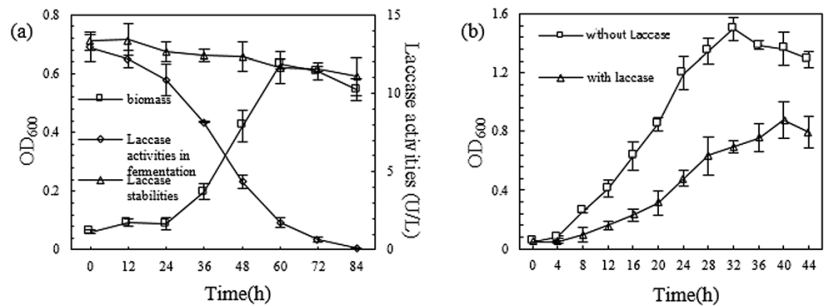

Fig. 4 (a) Growth of $B$. licheniformis $Y-1$ with the crude enzyme as carbon source; (b) influence of laccase on $B$. licheniformis $Y-1$ growth.
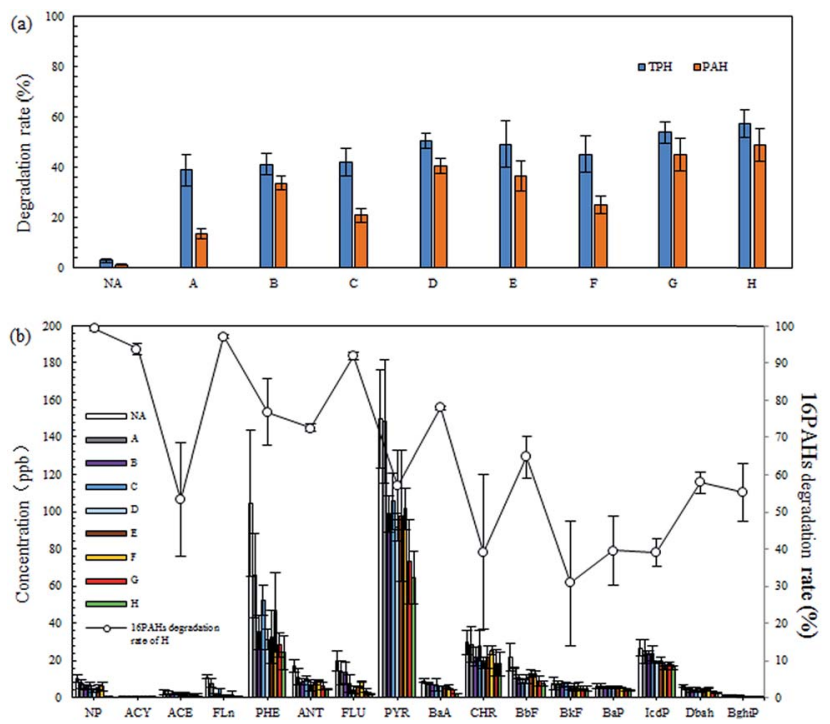

Fig. 5 (a) TPH degradation rate (\%) and total PAH degradation rate (\%) of each group, (b) GC-MS analysis of 16 PAHs of the experimental soil and $16 \mathrm{PAHs}$ biodegradation rate of the $\mathrm{H}$ group.

remediation technique, had the highest degradation rates for TPH and PAH, namely, $57.72 \pm 5.55 \%$ and $49.05 \pm 6.49 \%$, respectively. Its degrading effect was superior to that found when using only bacteria or fungi. Pozdnyakova et al. also came to a similar conclusion. ${ }^{17}$ Compared with other studies, the bacteria-fungi joint remediation used in this study showed a higher level of degradation effect on TPH and PAH at the $30^{\text {th }}$ day of remediation. ${ }^{\mathbf{4} 39-41}$ When other conditions were the same, the degradation effect of $P$. ostreatus $\mathrm{P} 1$ on petroleum hydrocarbons was better than that of B. licheniformis Y-1, which could be found in the degradation of PAH. As shown in Fig. 5(b), the degradation effects of P. ostreatus P1 on 16 types of PAH were all better than those of B. licheniformis Y-1. This was mainly attributed to the degrading enzymes system with strong functional agents secreted by $P$. ostreatus $\mathrm{P} 1 .^{18,22,24,27,39}$ By adding sand and straw, the degradation rates of TPH and PAH by B. licheniformis Y-1 were improved by $7.99 \%$ and $54.15 \%$ respectively, while those by $P$. ostreatus $\mathrm{P} 1$ were enhanced by $22.31 \%$ and $19.89 \%$, respectively. Combining the EC results (Fig. 2) with the laccase activity (Fig. 3), it was shown that adding sand and straw can enhance the activities of microorganisms in the soil, thus improving their degradation efficiency for petroleum hydrocarbons. After the addition of biosurfactant, the B. licheniformis Y-1 degradation rates of $\mathrm{TPH}$ and $\mathrm{PAH}$ were increased by $7.66 \%$ and $20.33 \%$ respectively, while those using $P$. ostreatus P1 were increased by $6.61 \%$ and $10.82 \%$ respectively. This was because the emulsification of biosurfactant made the petroleum hydrocarbons in the soil more easily usable by the microorganisms. ${ }^{31,32,42}$ In addition, as shown in Fig. 5(b), there was more PHE and PYR present in the soil, while only a little simple, volatile NP, ACY, and ACE as well as Dbah and BghiP with numerous $\mathrm{C}$ were found in the soil. With the increase in the $\mathrm{C}$ number of the $\mathrm{PAH}$, the microorganisms found it more 
difficult to degrade them, which matches those research results found using microbial methods for the remediation of petroleum-contaminated soil., ${ }^{4,17,25}$

\subsection{Comprehensive analysis of the remediation system}

Based on the above experimental results, it could be inferred that there was a relationship between the different components in the bacteria-white-rot fungi joint remediation (Fig. 6).

The degrading enzymes in the fungal remediation material were slowly released into the soil following the water. The enzymes decomposed the petroleum hydrocarbons in the soil by breaking the chemical bonds of the molecules of these complex petroleum hydrocarbons to generate short-chain petroleum hydrocarbons more easily utilised by microorganisms in the soil. Owing to the transfer of enzymes in the fungal remediation material to the soil, the concentration of enzymes in the fungal remediation material, and the rate of consumption of straw were reduced, thus prolonging the time taken to produce enzymes by the fungal remediation material. In the downward movement of water, not only enzymes, but also some fungi in the fungal remediation material, were carried downwards. The straw in the soil provided a framework for the growth of fungi. Moreover, during the growth on straw, fungi further secreted enzymes and the petroleum hydrocarbons in the soil were degraded simultaneously by bacteria and fungi. The sand in the soil improved the physical and chemical properties thereof and enhanced the activities of microorganisms in the soil. In particular, it accelerated the bacterial growth. Meanwhile, the emulsification of biosurfactant accelerated the dissolution and dispersion of petroleum hydrocarbons in the soil, thus making petroleum hydrocarbons more easily degraded by the microorganisms in the soil.

In addition, due to the large viscosity, petroleum hydrocarbons can bond soil particles, thus reducing the oxygen content in the soil. During the remediation, the fungal remediation material was more adaptable to the petroleum-contaminated soil's condition than the fungal liquid inoculant. In this study, inserting fungal remediation material into the soil was

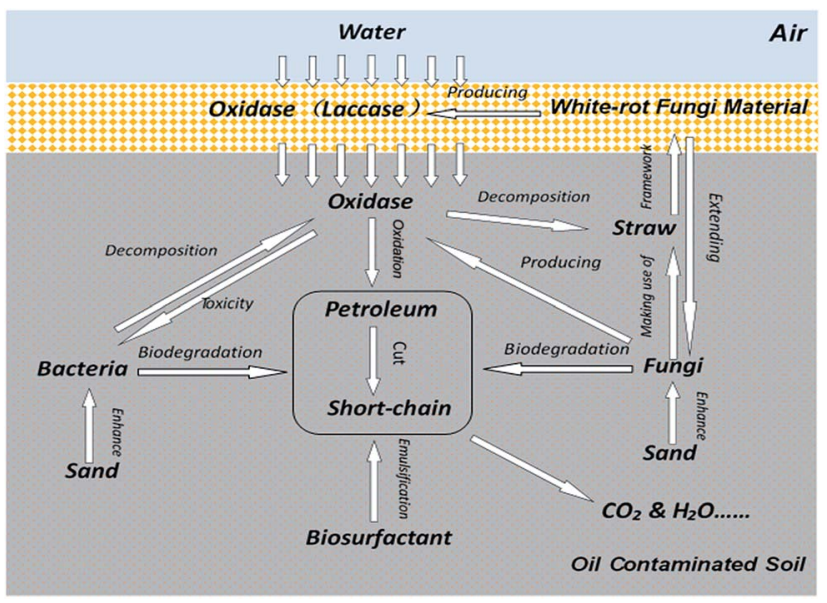

Fig. 6 Mechanism of bacteria-fungi joint remediation system. a better way to enhance the growth of white-rot fungi and guarantee the secretion of enzymes during the remediation, which could be found from the results of the experiments in Section 3.3 and 3.5 .

\section{Conclusions}

Based on the experimental results, bacteria-fungi joint remediation can effectively degrade petroleum hydrocarbons contained in soil and, in particular, the proposed method can degrade PAH. Higher laccase production and activity, the more stable growth situation of white-rot fungi, better TPH degradation rates and remediation results, indicate that the fungal remediation material has a huge potential in the remediation of petroleum-contaminated soil. The $P$. ostreatus $\mathrm{P} 1$ showed good synergy with $B$. licheniformis $\mathrm{Y}-1$ in petroleum hydrocarbon degradation. In addition, adding sand, straw, and biosurfactants could accelerate the degradation of petroleum hydrocarbons.

\section{Acknowledgements}

The authors are grateful for the financial support by the project "Fundamental Research Funds for the Central Universities (63161116)”, “International Joint Research Projects in the Science \& Technology Pillar Program of Tianjin, China (13RCGFSF14300)", and "Supported by the Fundamental Research Funds for the Central Public Welfare Research Institutes (TKS170204)".

\section{References}

1 M. J. Ayotamuno, R. B. Kogbara, S. O. T. Ogaji and S. D. Probert, Appl. Energy, 2006, 83, 1249-1257.

2 H. Charles, T. Pradeep, H. John, C. Cutler and J. Michael, Nature, 2003, 426, 318-322.

3 X. Li, X. Wang, Y. Zhang, L. Cheng, J. Liu, F. Li, B. Gao and Q. Zhou, RSC Adv., 2014, 4, 59803-59808.

4 D. Sarkar, M. Ferguson, R. Datta and S. Birnbaum, Environ. Pollut., 2005, 136, 187-195.

5 Y. P. Ting, H. L. Hu and H. M. Tan, Resour. Environ. Biotechnol., 1999, 2, 197-218.

6 Q. Zhou, F. Sun and R. Liu, Environ. Int., 2005, 31, 835-839.

7 Q. X. Zhou, Y. Teng and D. S. Lin, J. Agro-Environ. Sci., 2013, 32(2), 205-214.

8 E. Riser-Roberts, Remediation of petroleum contaminated soils: biological, physical, and chemical processes, 1998, vol. 10, pp. 332-362.

9 S. Kuppusamy, P. Thavamani, K. Venkateswarlu, Y. Bok Lee, R. Naidu and M. Megharaj, Chemosphere, 2017, 168, 944-968.

10 S. Kuppusamy, T. Palanisami, M. Megharaj, K. Venkateswarlu and R. Naidu, Rev. Environ. Contam. Toxicol., 2016, 236, 1-115.

11 X. Wang, Z. Cai, Q. Zhou, Z. Zhang and C. Chen, Biotechnol. Bioeng., 2012, 109, 426-433.

12 S. V. Mohan, T. Kisa, T. Ohkuma, R. A. Kanaly and Y. Shimizu, Rev. Environ. Sci. Bio/Technol., 2006, 5, 347-374. 
13 A. Haritash and C. Kaushik, J. Hazard. Mater., 2009, 169, 1-15.

14 S. Kuppusamy, T. Palanisami, M. Megharaj, K. Venkateswarlu and R. Naidu, Rev. Environ. Contam. Toxicol., 2016, 236, 117-192.

15 S. Kuppusamy, P. Thavamani, M. Megharaj and R. Naidu, Int. Biodeterior. Biodegrad., 2016, 108, 149-157.

16 M. Hassanshahian, M. S. Zeynalipour and F. H. Musa, Mar. Pollut. Bull., 2014, 82, 39-44.

17 N. N. Pozdnyakova, V. E. Nikitina, O. V. Turovskaya and I. Prikladnaia Biokhimiia, Microbiologia, 2008, 44, 60-65.

18 Y. Wu, Y. Teng, Z. Li, X. Liao and Y. Luo, Soil Biol. Biochem., 2008, 40, 789-796.

19 B. E. Andersson, S. Lundstedt, K. Tornberg, Y. Schnürer, L. G. Öberg and B. Mattiasson, Environ. Toxicol. Chem., 2003, 22, 1238-1243.

20 R. Canet, J. G. Birnstingl, D. G. Malcolm, J. M. Lopez-Real and A. J. Beck, Bioresour. Technol., 2001, 76, 113-117.

21 E. Torres, I. Bustos-Jaimes and S. Le Borgne, Appl. Catal., B, 2003, 46, 1-15.

22 C. McErlean, R. Marchant and I. M. Banat, Antonie van Leeuwenhoek, 2006, 90, 147-158.

23 A. D'Annibale, F. Rosetto, V. Leonardi, F. Federici and M. Petruccioli, Appl. Environ. Microbiol., 2006, 72, 28-36.

24 O. Potin, C. Rafin and E. Veignie, Int. Biodeterior. Biodegrad., 2004, 54, 45-52.

25 J. A. Bumpus, Appl. Environ. Microbiol., 1989, 55, 154-158.

26 C. S. Liao, S. Y. Yuan, B. H. Hung and B. V. Chang, J. Environ. Monit., 2012, 14, 1983-1988.

27 A. Gullotto, S. Branciamore, I. Duchi, M. Francisca Pareja Caño, D. Randazzo, S. Tilli, P. Giardina, G. Sannia,
A. Scozzafava and F. Briganti, Bioresour. Technol., 2008, 99, 8353-8359.

28 J. Jiang, H. Liu, Q. Li, N. Gao, Y. Yao and H. Xu, Ecotoxicol. Environ. Saf., 2015, 120, 386-393.

29 L. Gianfreda and M. A. Rao, Enzyme Microb. Technol., 2004, 35, 339-354.

30 M. Nagai, T. Sato, H. Watanabe, K. Saito, M. Kawata and H. Enei, Appl. Microbiol. Biotechnol., 2002, 60, 327-335.

31 L. Boqun, J. Meiting, L. Jinpeng, W. Wentao and L. Xiaojing, Mar. Pollut. Bull., 2016, 106, 301-307.

32 B. Liu, J. Liu, M. Ju, X. Li and Q. Yu, Mar. Pollut. Bull., 2016, 107, 46-51.

33 Y. Jiang, M. Ju, W. Li, Q. Ren, L. Liu, Y. Chen, Q. Yang, Q. Hou and Y. Liu, Bioresour. Technol., 2015, 197, 7-14.

34 C. E. Cerniglia, Biodegradation, 1993, 4, 331-338.

35 T. Sarachat, O. Pornsunthorntawee, S. Chavadej and R. Rujiravanit, Bioresour. Technol., 2010, 101, 324-330.

36 S. B. Batista, A. H. Mounteer, F. R. Amorim and M. R. Totola, Bioresour. Technol., 2006, 97, 868-875.

37 C. Hautphenne, M. Penninckx and F. Debaste, Environmental Technology \& Innovation, 2016, 5, 250-266.

38 P. Baldrian, FEMS Microbiol. Rev., 2006, 30, 215-242.

39 B. E. Andersson, L. Welinder, P. A. Olsson, S. Olsson and T. Henrysson, Bioresour. Technol., 2000, 73, 29-36.

40 X. Li, X. Wang, L. Wan, Y. Zhang, N. Li, D. Li and Q. Zhou, J. Chem. Technol. Biotechnol., 2016, 91, 267-275.

41 I. K. Kapdan, F. Kargi, G. McMullan and R. Marchant, Environ. Technol., 2000, 21, 231-236.

42 D. N. Singh and A. K. Tripathi, Bioresour. Technol., 2013, 128, 215-221. 